\title{
Environmental tobacco smoke exposure and asthma
}

\author{
Serap Argun Baris \\ Fusun Yildiz
}

Kocaeli University Faculty of Medicine, Department of Pulmonary Diseases, Kocaeli, Turkey

\author{
Address for correspondence: \\ Serap Argun Baris, MD \\ Kocaeli University Faculty of Medicine \\ Department of Pulmonary Diseases \\ Umuttepe, Kocaeli, Turkey \\ Phone: +902623037211 \\ E-mail: serapargun2002@yahoo.com
}

\section{Summary}

Environmental Tobacco Smoke (ETS) exposure is a major health problem over the world. There are growing proofs supporting a relationship between environmental tobacco smoke exposure and development of asthma in childhood and even in adulthood. On the other hand, passive smoking is related to worsening of asthma symptoms, increase of exacerbations, therapy use and also worsening in pulmonary function tests and bronchial hyperresponsiveness. These results reveal the importance of avoid from passive smoking both in healthy individuals and asthmatic patients for the prevention or control of the asthma.

KEY WORDS: asthma, environmental tobacco smoke, asthma control.

\section{Introduction}

Asthma is a chronic inflammatory disease characterized by reversible airway obstruction, bronchial hyperresponsiveness and inflammatory cell infiltration of the airways with activated $T$ cells and eosinophils. The genetic and environmental factors have a key role in the etiology of the disease. Smoking is one of the environmental factors which have been encountered in the various stages of the life.
The smoking history of the mother in pregnancy period and the environmental tobacco exposure in childhood are the risk factors of new onset of asthma. At the same time, passive smoking increases the asthma symptoms and cause difficult to control of asthma. It is known that smoking accelerate the annual decline of pulmonary function test, increase the severity of asthma and decrease the treatment response of the disease (1).

\section{Passive smoking and asthma}

A complex mixture of over 4000 chemical compounds, second hand tobacco smoke contains potent respiratory irritants such as sulfur dioxide, ammonia, formaldehyde, and acrolein (2). These respiratory irritants may cause the development of asthma via the irritant and immunological mechanisms. Also they may increase the symptoms of asthma in current asthmatics (3).

Passive smoking is common but the prevalence varies widely between the different countries. The rates of environmental tobacco smoke (ETS) expo-
Up to $60-84 \%$ of the adult asthmatic may have passive smoking exposure. sure are high in many popula-

tions. These rates may change according to sociocultural and legal characteristics of the countries. In the European Community Respiratory Health Survey which was conducted in 36 centers of 16 countries, more than half of the participants were regularly involuntarily exposed to tobacco smoke. The prevalence of passive smoking in the workplace varied from $2.5 \%$ in Sweden, to $53.8 \%$ in Spain (4). It was suggested that nearly half of the population had environmental tobacco smoke exposure despite the smoking bans in USA (3). The passive smoking rates were $68 \%$ in men and $64 \%$ in women in a study that included 42,721 participants aged over 15 in USA (5). The passive smoking exposure rate of the asthmatic children and adults was $42 \%$ in Canada (6). Environmental tobacco smoke in the home was found in $41 \%$ (maternal smoking during pregnancy $18 \%$, smoking mother $32 \%$, and smoking father $38 \%$ ) of the children in Lizbon (7). Another study which evaluated the exposure via the direct measurements suggested that the $60-84 \%$ of the adult asthmatics had passive smoking exposure (8). These findings indicate that both asthmatics and healthy individuals expose to passive smoke. 
The role of environmental tobacco smoke exposure on development of asthma

There is a growing evidence of a causal association between environmental tobacco smoke exposure and development of asthma in childhood and even in adulthood.

\section{Smoking during pregnancy}

There are many studies that report the causative relationship between the childhood asthma and environmental tobacco smoke exposure. These results include the effects of passive smoking on prenatal or postnatal period. It was found that the lung functions were decreased and the risk of wheeze increased in children with maternal smoking history during the pregnancy. The lung functions were lower in the babies who had history of smoking exposure during the fetal period and presence of asthma in family members. It was also sug-
The immune system of babies exposed during pregnancy to smoking is more deviated toward the allergic and asthmatic inflammatory phenotype and making them more prone to develop asthma later in their life. gested that the presence of these factors together might affect the development of lung tissue during the intrauterine period (9)

The placenta does not offer any barrier to the penetration of ETS into the fetus. If the mother had passive or active smoking exposure, fetuses exposed to ETS via the umbilical cord blood. The immune system in these babies is more deviated toward the allergic and asthmatic inflammatory phenotype and therefore makes them more prone to develop asthma later in their life (10).

Recent studies showed that the environmental tobacco smoke exposure associated with increased prevalence of respiratory tract infections, wheeze, and asthma. A study that evaluated the effects of maternal smoking during pregnancy on asthma and wheezing in 5,762 school-aged children showed that in utero exposure to maternal smoking was associated with increased prevalence of physician-diagnosed asthma [odds ratio $(O R)=1.8$ ], asthma with current symptoms $(O R=2.3)$, asthma requiring medication use in the previous 12 months $(O R=2.1)$, lifetime history of wheezing $(\mathrm{OR}=1.8)$, and emergency room visits during the previous year $(\mathrm{OR}=3.4)(11)$. Also, the exposure to prenatal maternal smoking was associated with increase in risk of wheeze (40\%) and asthma (20\%) in children aged $\leq 2$ years in a systematic review that included 79 prospective studies (OR=1.41 and OR=1.85) (12). Silvestri et al. (13) reported that exposure to maternal prenatal smoking was associated with an increased risk of wheezing in $<6$-year-olds $(\mathrm{OR}=1.36)$ and wheezing or asthma in $\geq 6$-year-olds $(\mathrm{OR}=1.22)$ in a systematic review. They confirmed an important role of prenatal exposure to maternal smok- ing on the induction of wheezing and asthma, particularly in the first years of life (13). Oh et al. (14) showed that poor asthma control among children 8-17 years of age was independently associated with in utero smoking (OR:1.5). In utero smoking via the mother was also associated with secondary asthma outcomes, including early onset asthma $(\mathrm{OR}=1.7)$, daytime symptoms $(\mathrm{OR}=1.6)$, and asthma related limitations of activities $(O R=1.6)$ (14). Recently, Wang et al. (15) found that women who lacked a gene that codes for a detoxifying enzyme only gave birth to low-birth-weight babies if they smoked tobacco (15). These studies illuminate the interplay of genes and environmental influences, like tobacco (Figure 1). They also indicate that we can prevent disease simply by eliminating exposures to environmental hazards.

\section{Passive smoking in childhood and adulthood}

There are lots of studies reported that the relationship between the environmental tobacco smoke exposure and wheeze. However, the effect of the environmental tobacco exposure on onset of asthma is controversial. It was found that $46 \%$ of the preschool children with wheeze had a history of exposure to passive smoking in a period of the life (16). Gilliland et al. reported that maternal smoking during pregnancy increased the occurrence of physician-diagnosed asthma and wheezing during childhood. On the other hand, current ETS exposure was associated with wheezing, but not physician-diagnosed asthma (11). Also, Silvestri et al. suggested that postnatal exposures to maternal/parental smoking were associated with wheezing in
One group of people most likely to benefit from this legislation is bar workers, who are exposed to high levels of secondhand smoke as part of their occupation. $<6$-year-olds $(\mathrm{OR}=1.21$ and $\mathrm{OR}=1.30)$ but exclusive postnatal exposure was not related with wheezing or asthma (13).

In contrast, Goodwin et al. (17) reported that household smoking was associated with a statistically significant increase in the risk of asthma among children with age of $0-17$ years old in USA ( $p=0.026)$.

The effects of the environmental tobacco exposure on onset of asthma have been studied especially in childhood period. The relationship between the passive smoking in adulthood and onset of asthma are not well known. Recently there are some proofs about the causative relationship between the onset of asthma and passive smoking exposure. In the SAPALDIA study, the association between passive exposure to tobacco smoke and respiratory symptoms was examined in a sample of 4,197 never-smoking adults (18-60 years old) via a questionnaire in Switzerland. Passive smoking exposure was associated with an elevated risk of wheezing (OR=1.94), an elevated risk of dyspnea $(O R=1.45)$, and an elevated risk of physician diagnosed asthma (OR=1.39). The association of passive smoking exposure with dyspnea, wheeze, and 


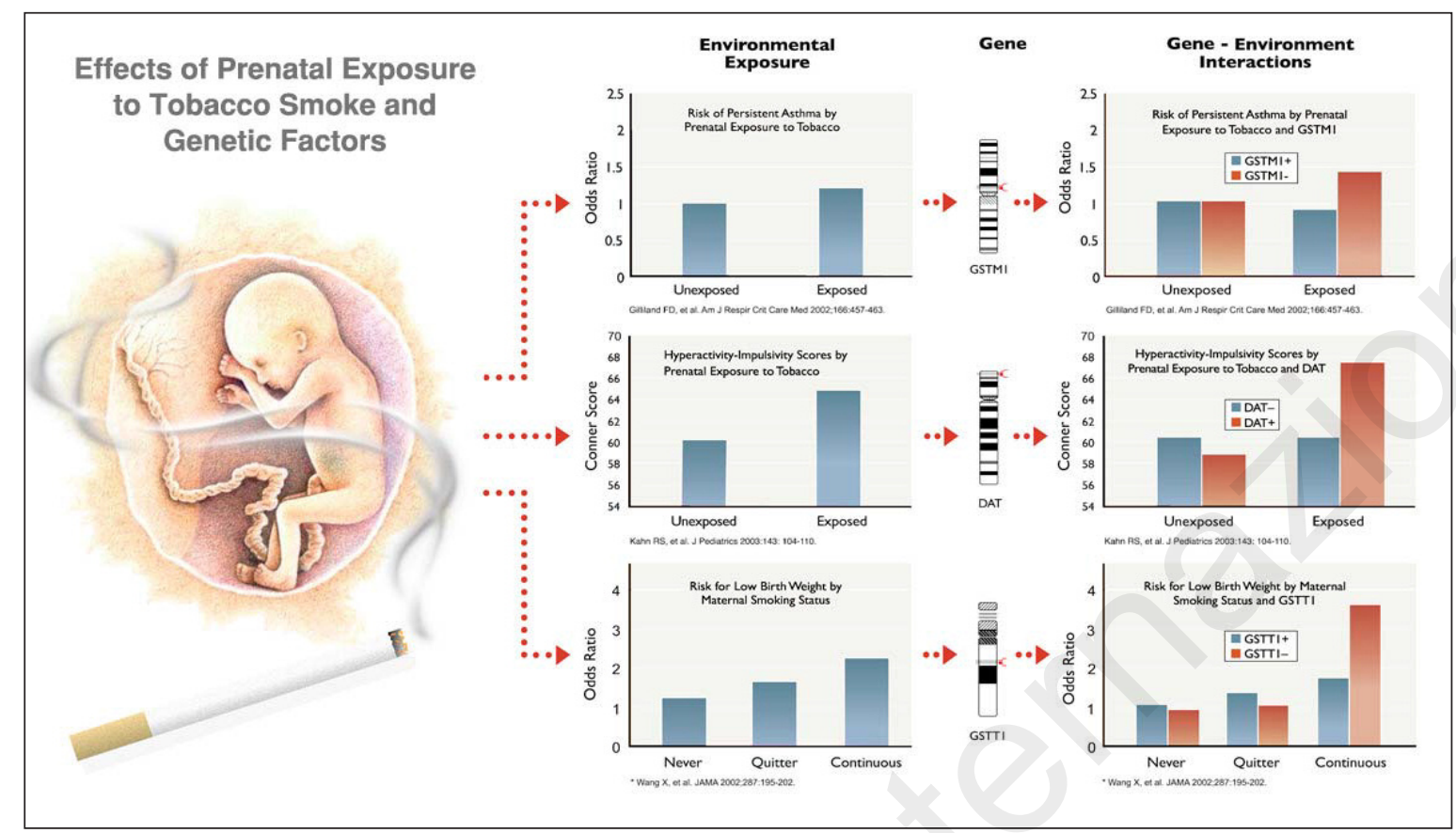

Figure 1 - Effects of prenatal exposure to tobacco smoke and genetic factors on risk of persistent asthma and other health problems (adapted from http://www.ehatlas.ca).

asthma showed evidence of a dose-dependent increase with hours per day of exposure (18). Larson et al. evaluated the impact of exposure to environmental tobacco smoke during childhood on asthma prevalence in adulthood and they reported that the prevalence of physician-diagnosed asthma was higher in exposed subjects than non-exposed subjects $(7.6 \%$ and $5.9 \%, p=0.036)$. Childhood exposure to ETS was associated with an increased prevalence of asthma among never-smoker adults, especially in nonatopic subjects (19).

The European Community Respiratory Health Survey (4) showed that passive smoking was significantly associated with increased bronchial responsiveness $(\mathrm{OR}=-0.18)$, while passive smoking in the workplace was significantly associated with all types of respiratory symptoms and current asthma $(\mathrm{OR}=1.90)$. No significant association was found between passive smoking and total serum IgE (4). These findings of positive correlation between the bronchial hyperresponsiveness and passive smoking exposure strongly support the role of passive smoking on the onset of asthma. Gupta et al. (20) reported that the prevalence of asthma in the ETS exposed subjects was higher compared to non-exposed individuals $(2.2 \%$ and $1.9 \%, p<0.05)$ in India. Multiple logistic regression analysis showed a higher risk of having asthma in persons who were exposed to ETS compared to those not exposed $(\mathrm{OR}=1.22)$ after adjusting for age, gender, usual residence, exposure to biomass fuels and atopy. Stratification of ETS exposure revealed that exposure during childhood and both during childhood and adulthood were significantly associated with asthma prevalence. Exposure only in adulthood period was not a significant risk factor $(\mathrm{OR}=1.13)$. Persons who reported combined environmental tobacco smoke exposure from parents during childhood and adulthood had the highest risk of having asthma $(O R=1.69)$. Environmental tobacco smoke exposure was also significantly associated with prevalence of respiratory symptoms such as wheezing, cough and breathlessness (20). Jakkola et al. (21) compared the subjects that new diagnosed asthma in adulthood with control. Risk of asthma was related to workplace ETS exposure $(\mathrm{OR}=2.16)$ and home exposure $(\mathrm{OR}=4.77)$ in the past year. Cumulative ETS exposure over a lifetime at work and at home increased the risk. This study indicated that both cumulative lifetime and recent ETS exposures increased the risk of adult-onset asthma (21).

The role of passive smoking exposure on developing adult asthma has been studied also in Cohort studies (22). A respiratory questionnaire administered to 3914 nonsmoking adults in 1977 and again in 1987 for evaluating the association occupational and air pollutant exposure with the development of adult asthma (22). These Authors suggested (22) that second-hand smoke exposure in work site was associated with the development of asthma $(\mathrm{OR}=1.45)$.

As the harmful effects of secondhand smoke become more widely appreciated, most of the countries have attempted to limit the health risks of the population by prohibiting smoking in public places. One group of people most likely to benefit from this legislation is bar workers, who are exposed to high levels of secondhand smoke as part of their occupation (23). Allwrights et al. (24) compared the salivary cotinine concentration and self reported exposure to secondhand smoke 
before and after the smoke free legislation in nonsmoking bar workers in Ireland. It was found that the salivary cotinine concentrations dropped by $80 \%$ after the smoke-free law and changes in self reported exposure to secondhand smoke were consistent with the changes in cotinine concentrations (24). A Cochrane Database review (25) reported consistent evidence that smoking bans reduced exposure to second-hand smoke (SHS) exposure in workplaces, restaurants, pubs and in public places. There was a greater reduction in exposure to SHS in hospitality workers compared to the general population. But, there was no change in either the prevalence or duration of reported exposure to SHS in the home as a result of implementing legislative bans (25).

The association between the environmental tobacco exposure and development of asthma has been evaluated various sites such as home and work place in both childhood and adulthood period in many studies. The results were similar in different countries and different populations in the world. All these results support the causative relationship between the passive smoking and the development of asthma.

The role of exposure to environmental tobacco smoke on current asthma

The asthmatic patients are more susceptible to the irritant effects of smoking because of the chronic airway inflammation. Most of the asthmatic patient state that the cigarette smokes trigger the symptoms of The bronchial hyper
responsiveness was
significantly higher
in tobacco exposed
asthmatic women
than non-exposed
ones. asthma. The studies about the association between environmental smoke exposure and development of asthma also present the adverse effects of ETS on current asthma.

Recent studies suggest that passive smoking increase the asthma symptoms and cause difficult to control of asthma (26). Lang et al. (27) found that children with domestic indoor exposure had worse asthma control $(p=0.04)$, and worse $\mathrm{FEV}_{1} \%$ predicted $(\mathrm{p}=0.02)$. And, it was suggested that domestic smoking exposure was associated with both higher rates of symptomatic respiratory infection and poorer asthma control despite generally intensive controller therapy. Jindal et al. (28) showed that the account of emergency department (ED) visits, acute episodes, and bronchodilators per patient and corticosteroid requirement were significantly high $(p<0.01)$ in the ETS-exposed asthmatic patients. Furthermore, the FEV 1 values were lower in ETS-exposed asthmatics than nonexposed ones $\left(\mathrm{FEV}_{1} \% 68.7\right.$ and \%80.8). Jindal et al. (28) suggested that the control of asthma was poorer in adult patients with asthma exposed to ETS at home and/or at work (28) than non-exposed subjects. It was suggested that the ETS exposure was associated with decreased levels of $F E V_{1}, F V C$ and $F F_{25-75}$ in especially women in the SAPALDIA study (17). The bronchial hyper-responsiveness was significantly higher in the ETS exposed asthmatic women than non-exposed ones $(p<0.05)$ although there was no significant difference in $\mathrm{FEV}_{1}$ and $\mathrm{FEV} / \mathrm{FVC}$ among the groups (29). In a prospective Cohort study, it was shown that exposure to ETS was related to poorer physical health status and asthma specific quality of life. Moreover, ETS exposure was associated with a greater risk of emergency department visits (30).

\section{Low dose environmental tobacco exposure}

The parents of children with asthma often avoid smoking in their homes or near their children, thus limiting exposure (31). The definition of the low dose ETS is the exposure of environmental tobacco smoke in children with asthma whose parents either deny smoking or only smoke outside the home. In a study evaluated the effects Preschool children exposure even to low environmental tobacco levels may have altered lung function. of low-level environmental tobacco smoke (ETS) exposure in asthmatic children reported that only one parent reported smoking in the home. However, 70\% of the children had urinary cotinine levels $\geq 1 \mathrm{ng} / \mathrm{ml}$, has suggested ETS exposure (32). Valsamis et al. (31) evaluated the relationship between low-level ETS exposure and pulmonary function tests (PFTs) in preschool children with asthma. They found that $\mathrm{FEV}_{1}$ level was lower in subjects with a urinary cotinine level $\geq 5 \mathrm{ng} / \mathrm{ml}$ as compared to those with levels $<1 \mathrm{ng} / \mathrm{ml}$ or between 1 and $5 \mathrm{ng} / \mathrm{ml}$; both at baseline and after inhalation of albuterol. These findings suggest that despite parental denial of smoking close to their children, preschool children exposure even to low enviromental tobacco levels may have altered lung function, possibly in a dose-dependent manner (31).

As a result, the evidences about causative relationship between onset of asthma and environmental tobacco exposure during the childhood or adult periods have been increased. On the other hand, passive smoking is related to worsening of asthma symptoms, increase of exacerbations, therapy use and also worsening in pulmonary function tests and bronchial hyperresponsiveness. The literature's evidence reveals the importance to avoid passive smoking both in healthy people and asthmatic patients.

\section{References}

1. Mungan D. Smoking and asthma. Turkiye Klinikleri J Allergy-Special Topics. 2009;2(2):14-21.

2. California Environmental Protection Agency. Health effects of exposure to environmental tobacco smoke. Sacramento, CA: Office of Environmental Health Hazard Assessment, 1997.

3. Eisner MD. Passive smoking and adult asthma. Immunol Allergy Clin N Am. 2008;28:521-37. 
4. Janson C, Chinn S, Jarvis D, Zock JP, Torén K, Burney $P$, et al. Effect of passive smoking on respiratory symptoms, bronchial hyperresponsiveness, lung function, and total serum IgE in the European Community Respiratory Health Survey: a cross-sectional study. Lancet. 2001;358(9299):2103-9.

5. Iribarren C, Friedman GD, Klatsky AL, Eisner MD. Exposure to environmental tobacco smoke: association with personal characteristics and self reported health conditions. J Epidemiol Community Health. 2001;55(10):721-8.

6. Leech JA, Wilby K, McMullen E. Environmental tobacco smoke exposure patterns: a subanalysis of the Canadian Human Time-Activity Pattern Survey. Can J Public health. 1999;90(4):244-9.

7. Constant C, Sampaio I, Negreiro F, Aguiar P, Silva A, Salgueiro M, et al. Environmental tobacco smoke (ETS) exposure and respiratory morbidity in school age children. Rev Port Pneumol. 2011;17(1):20-6.

8. Eisner MD, Klein J, Hammond SK, Koren G, Lactao $G$, Iribarren $C$. Directly measured second hand smoke exposure and asthma health outcomes. Thorax. 2005; 60(10):814-21.

9. Stick SM, Burton PR, Gurrin L, et al. Effects of maternal smoking during pregnancy and a family history of asthma on respiratory function in newborn infants. Lancet. 1996;348:1060-4.

10. Cheraghi M, Salvi S. Environmental tobacco smoke (ETS) and respiratory health in children. Eur J Pediatr. 2009;168(8):897-905.

11. Gilliland FD, Li YF, Peters JM. Effects of maternal smoking during pregnancy and environmental tobacco smoke on asthma and wheezing in children. Am J Respir Crit Care Med. 2001;163(2):429-36.

12. Burke H, Leonardi-Bee J, Hashim A, Pine-Abata $H$, Chen Y, Cook DG, et al. Prenatal and passive smoke exposure and incidence of asthma and wheeze: systematic review and meta-analysis. Pediatrics. 2012;129(4):735-44.

13. Silvestri M, Franchi S, Pistorio A, Petecchia L, Rusconi F. Smoke exposure, wheezing, and asthma development: A systematic review and meta-analysis in unselected birth cohorts. Pediatr Pulmonol. 2014 Mar 20. doi: 10.1002/ppul.23037.

14. Oh SS, Tcheurekdjian H, Roth LA, Nguyen EA, Sen S, Galanter JM, et al. The impact of secondhand smoke on asthma control among Black and Latino children. J Allergy Clin Immunol. 2012;129(6):147883.

15. Wang X, Zuckerman B, Pearson C, et al. Maternal cigarette smoking, metabolic gene polymorphism, and infant birth weight. JAMA. 2002 Jan 9;287:195202.

16. Baena-Cagnani CE, Gomez RM, Baena-Cagnani R, Canonica W. Impact of environmental tobacco smoking on the development and outcomes of asthma and rhinitis. Curr Opin Allergy Clin Immunol. 2009;9:13640.

17. Goodwin RD, Cowles RA. Household smoking and childhood asthma in the United States: a state-level analysis. J Asthma. 2008;45:607-10.
18. Leuenberger P, Schwartz J, Ackermann - Liebrich U, Blaser K, Bolognini G, Bongard JP, et al. Passive smoking exposure in adults and chronic respiratory symptoms (SAPALDIA Study). Am J Respir Crit Care Med. 1994;150(5 pt 1):1222-8.

19. Larson ML, Frisk M, Hallstrom J, Kiviloog J, Lundbäck B. Environmental tobacco smoke exposure during childhood is associated with increased prevalence of asthma in adults. Chest. 2001;120:711-17.

20. Gupta D, Aggarwal AN, Chaudhry K, Chhabra SK, D'Souza GA, Jindal SK, et al. Household environmental tobacco smoke exposure, respiratory symptoms and asthma in non-smoker adults: a multicentric population study from India. Indian J Chest Dis Allied Sci. 2006;48(1):31-6.

21. Jaakkola MS, Piipari R, Jaakkola N, Jaakkola JJ. Environmental tobacco smoke and adult onset asthma: a population-based incident case control study. Am J Public Health. 2003;93(12):2055-60.

22. Greer JR, Abbey DE, Burchette RJ. Asthma related to occupational and ambient air pollutants in nonsmokers. J Occup Med. 1993;35(9):909-15.

23. Menzies D, Nair A, Williamson PA, Schembri S, AlKhairalla MZ, Barnes M, et al. The impact of legislative ban on smoking in public places on the quality of health, pulmonary function and inflammation of bar workers in Scotland. JAMA. 2006;296(14):1742-8.

24. Allwright S, Paul G, Greiner B, Mullally BJ, Pursell L, Kelly A, et al. Legislation for smoke-free workplaces and health of bar workers in Ireland: before and after study. BMJ. 2005 Nov 12;331(7525):1117. Epub 2005 Oct 17.

25. Callinan JE, Clarke A, Doherty K, Kelleher C. Legislative smoking bans for reducing secondhand smoke exposure, smoking prevalence and tobacco consumption. Cochrane Database Syst Rev. 2010 Apr 14;(4):CD005992.

26. Eisner MD, Yelin EH, Katz PP, Earnest G, Blanc PD. Exposure to indoor combustion and adult asthma outcomes: environmental tobacco smoke, gas stoves and wood smoke. Thorax. 2002;57(11):973-8.

27. Lang JE, Dozor AJ, Holbrook JT, Mougey E, Krishnan S, Sweeten S, et al. American Lung AssociationAsthma Clinical Research Centers. Biologic mechanisms of environmental tobacco smoke in children with poorly controlled asthma: results from a multicenter clinical trial. J Allergy Clin Immunol Pract. 2013;1(2):172-80.

28. Jindal SK, Gupta D, Singh A. Indices of morbidity and control of asthma in adult patients exposed to environmental tobacco smoke. Chest. 1994;106(3):7469.

29. Eisner MD. Environmental tobacco smoke exposure and pulmonary function among adults in NHANES III: impact on the general population and adults with current asthma. Environ Health Perspect. 2002;110 (8):765-70.

30. Eisner MD, Katz PP, Yelin EH, Hammond SK, Blanc PD. Measurement of environmental tobacco smoke exposure among adults with asthma. Environ Health Perspect. 2001;109(8):809-14. 
31. Valsamis C, Krishnan S, Dozor AJ. The effects of lowlevel environmental tobacco smoke exposure on pulmonary function tests in preschool children with asthma. J Asthma. 2014 Feb 28. [Epub ahead of print]
32. Gill R, Krishnan S, Dozor AJ. Low-level environmental tobacco smoke exposure and inflammatory biomarkers in children with asthma. J Asthma. 2014; 51(4):355-9. 